\title{
A Study on Different Dairy Farming Systems and Their Productivity in Kerala
}

\author{
Sabin George ${ }^{1 *}$, Saseendran P.C. ${ }^{2}$, Anil K.S. ${ }^{2}$, Gleeja V.L. ${ }^{2}$ and Pramod S. ${ }^{3}$ \\ ${ }^{1}$ College of Veterinary and Animal Sciences, Pookode, Wayanad, Kerala, INDIA \\ ${ }^{2}$ College of Veterinary and Animal Sciences, Mannuthy, Thrissur, Kerala, INDIA \\ ${ }^{3}$ Livestock Research Station, Thiruvazhamkunnu, Palakkad, Kerala, INDIA \\ "Corresponding author: S George; E-mail: sabin@kvasu.ac.in
}

\begin{abstract}
The study conducted was among farmers who were members of dairy co-operatives in different agro- climatic zones of Kerala with the objective to identify dairy farming systems and to document productivity. It was observed that small holders operated 83.80 per cent of the farms. Eight farming systems based on cropping patterns were identified. Mixed farming was the largest system with 50.0 per cent of the sampled units while systems based on mono cultures of paddy, coconut or rubber constituted 27.20 per cent and homestead farms accounted to 20.6 per cent of the studied farms. The average peak yield ranged from $14.63 \pm 0.37$ (litres) in small farms to $18.64 \pm 0.54$ (litres) in large farms. Test day yields were $9.61 \pm 0.30$ in small farms and $12.58 \pm 0.68$ in large farms. Peak yields, test day yields and predicted lactation yields differed significantly between types of farms $(\mathrm{P}<0.01)$. Service period $(128.53 \pm 7.96$ days $)$ and inter calving period $(408.53 \pm 7.96)$ were significantly shorter $(\mathrm{P}<0.01)$ in large farms than in small or medium farms.
\end{abstract}

\section{HIGHLIGHTS}

(0 Eight farming systems based on crops were identified in Kerala.

(0 Small holders operated 83.80 percent of dairy farms in Kerala.

0 Large farms had higher peak yield, shorter inter calving period and service period.

Keywords: Small holder, livestock production, farming system

Agriculture sector in Kerala had undergone tremendous change over the past 50 years. Focus shifted away from food crop production to cash crops. Subsequently, cropping area of rice declined and that of cash crops like rubber increased (Viswanathan, 2014). Studies in more recent times also point to a similar trend. While paddy cultivation recorded negative growth, cropping areas of banana and rubber improved. Crop diversification index also reflected the increasing trend of mono cropping in favour of non food crops in the state (Rejula and Singh, 2015).

Traditionally, dairying was practised in association with paddy cultivation in the state. Various researchers identified different dairy production systems based on many criteria like herd size, ownership pattern, income sources, dry matter availability, cropping pattern, peculiarity of geographical area, peculiarity of cattle keepers, method of cattle keeping, type of animal and feeds used etc. The importance of such studies and the need for livestock development programme to be best applied through some form of Farming Systems Research/Extension approach (FSR/E) was highlighted by Sastry and Thomas (2015).

However there was only limited number of studies which focussed on different dairy production systems operating in the state recently. The present study attempted to fill this gapand was conducted in five districts of Kerala representing its agro-climatic zones (NARP, 1989) during

How to cite this article: George, S., Saseendran, P.C., Anil, K.S., Gleeja V.L. and Pramod, S. (2020). A study on different dairy farming systems and their productivity in Kerala. J. Anim. Res., 10(4): 615-621.

Source of Support: None; Conflict of Interest: None 
2016-17. The objectives were to document prevailing dairy farming systems in the state and to compare their productivity. The study first identified dairy production systems based on number of milch cows (KAU, 2010) and categorised them into small, medium and large units. Within each farm category thereof, more production systems based on major crop/cropping pattern, relative income from different farming activities and dry matter availability to animals were identified. The study also observed important dairy economic parameters among different systems of farming.

\section{MATERIALS AND METHODS}

A stratified multistage random sampling procedure was used to select the area of study and respondents. In the first stage, the state of Kerala was stratified into five agroclimaticzones (NARP, 1989). In the secondstage one district from each zone (Strata) wasrandomly selected. In the third stage, from each district two blocks were randomly selected. Subsequently, Pathanamthitta (South Zone), Thrissur (Central Zone), Palakkad (North Zone), Alappuzha (Wet Land) and Wayanad (High land Zone) representing agro-climatic zones of the state were included in the study. The blocks sampled were Parakode and Pandalam in the South zone. In central zone, Ollukkara and Irinjalakuda blocks were selected, while in north zone Kuzhalmannam and Chittur blocks were selected for the study. Likewise, Haripad and Veliyand blocks of wet land zone as well as Mananthavady and Kalpetta blocks in highland were included in the study.

The respondents selectedwere dairy farmers who were members ofthe dairy co-operatives and enrolled in the Direct Benefit Transfer (DBT) scheme of the government of Kerala. As the total population of milk producers and DBT members were nearlytwo lakhs, a total sample of 350 farmers was selected for the present study. The farmers/ farm households were categorized (KAU, 2010) into small or subsistence farms (1-2 cows), medium (3-10 cows) and large farms (more than 10 cows). After identifying the farming system based on farm size, they were further classified on the basis of major crop or cropping pattern of the farm; share to total farm income and contribution of dry matter/feed to livestock. The numbers of small, medium andlarge farms included in the study were 175, 100 and 75 respectively, which was determined inproportion to the number of farmers available ineach class. The sample size for each category of farms in each block was determined inproportion to the number of farmers belonging to each category.

Primary data was collected by means of observation, measurement, in-depth interview and pre tested questionnaire. Data pertaining to economic characters like peak yield, age at first successful service, age at first calving, inter calving interval, service period and number of artificial inseminations (AI) per conception were collected from farmers based on verifiable records. Milk yields were recorded on the day of visit (Test day milk yield). Records of fat and SNF content of milk on test day were collected from co-operative society. Wet and dry averages were calculated using the formulae given below.

Wet average $=\frac{\text { Total milk produced in the farm }}{\text { Number of animals in milk }}$
Dry average $=\frac{\text { Total milk produced }}{\text { Number of milch animals }}$

Lactation yields were predicted using methods developed by Kerala Agricultural University (KAU, 2010). The results were analysed using simple statistical tools like frequencies and percentage. Production data was analysed using one way ANOVA, using SPSS (version 24).

\section{RESULTS AND DISCUSSION}

The details of distribution of small, medium and large farms are presented in Table 1. Results indicated that out of 23,614 dairy households enumerated in 10 blocks, small holders operated 83.80 per cent of the farms, while large entrepreneurs accounted to less than one per cent of all such enterprises. Medium dairy farms with 3-10 milch cattle also had notable presence which proved the suitability of dairying as a commercial venture. Veliyanad block in Alappuzha district and Chittur block in Palakkad district had the biggest share of large farms $(2.4 \%)$ and medium farms (31.90\%) respectively. Alappuzha and Palakkad districts traditionally had large areas under paddy cultivation. The availability of crop residues and demand for organic fertilizer could be cited as reasons for this observation (Thomas, 2011). The patterns of distribution of small, medium and large farms in other blocks studied were more or less uniform. 
Table 1: Dairy farming systems identified based on number of milch animals in selected block

\begin{tabular}{|c|c|c|c|c|c|c|c|c|c|}
\hline \multirow{3}{*}{ Sl. No. } & \multirow{3}{*}{$\begin{array}{l}\text { Agro-climatic zone } \\
\text { (District) }\end{array}$} & \multirow{3}{*}{ Name of block } & \multicolumn{6}{|c|}{ Basic types of farms ( $n=$ frequency) } & \multirow{3}{*}{$\begin{array}{l}\text { Total } \\
\mathrm{n}\end{array}$} \\
\hline & & & \multicolumn{2}{|c|}{ Small } & \multicolumn{2}{|c|}{ Medium } & \multicolumn{2}{|c|}{ Large } & \\
\hline & & & $\mathbf{n}$ & $\%$ & $\mathbf{n}$ & $\%$ & n & $\%$ & \\
\hline \multirow[t]{2}{*}{1} & \multirow{2}{*}{$\begin{array}{l}\text { South Kerala } \\
\text { (Pathanamthitta) }\end{array}$} & Parakode & 1305 & 86.80 & 194 & 12.90 & 4 & 0.30 & 1503 \\
\hline & & Pandalam & 672 & 85.0 & 117 & 14.80 & 2 & 0.30 & 791 \\
\hline \multirow[t]{2}{*}{2} & \multirow{2}{*}{ Central Kerala (Thrissur) } & Ollukkara & 1308 & 86.10 & 206 & 13.60 & 5 & 0.30 & 1519 \\
\hline & & Irinjalakuda & 391 & 82.10 & 80 & 16.80 & 5 & 1.10 & 476 \\
\hline \multirow[t]{2}{*}{3} & \multirow{2}{*}{ North Kerala (Palakkad) } & Kuzhalmannam & 2297 & 92.20 & 183 & 7.30 & 11 & 0.40 & 2491 \\
\hline & & Chittur & 3402 & 67.0 & 1620 & 31.90 & 58 & 1.10 & 5080 \\
\hline \multirow[t]{2}{*}{4} & \multirow{2}{*}{$\begin{array}{l}\text { Problem Zone (Alappuzha: } \\
\text { Kuttanad wet lands) }\end{array}$} & Haripad & 715 & 78.70 & 188 & 20.70 & 6 & 0.70 & 909 \\
\hline & & Veliyanad & 176 & 69.30 & 72 & 28.30 & 6 & 2.40 & 254 \\
\hline \multirow[t]{3}{*}{5} & \multirow{2}{*}{ High Range (Wayanad) } & Mananthavady & 5767 & 90.0 & 612 & 9.60 & 29 & 0.50 & 6408 \\
\hline & & Kalpetta & 3756 & 89.80 & 417 & 10.0 & 10 & 0.20 & 4183 \\
\hline & Total & & 19789 & 83.80 & 3689 & 15.62 & 136 & 0.58 & 23614 \\
\hline
\end{tabular}

Table 2: Dairy farming systems identified based on the major crop/cropping pattern

\begin{tabular}{|c|c|c|c|c|c|c|c|c|c|}
\hline \multirow{3}{*}{ Sl. No. } & \multirow{3}{*}{$\begin{array}{l}\text { Major crop/ Cropping } \\
\text { pattern }\end{array}$} & \multicolumn{6}{|c|}{ Basic types of farms $(n=$ frequency $)$} & \multirow{2}{*}{\multicolumn{2}{|c|}{ Overall }} \\
\hline & & \multicolumn{2}{|c|}{ Small } & \multicolumn{2}{|c|}{ Medium } & \multicolumn{2}{|c|}{ Large } & & \\
\hline & & $\mathbf{n}$ & $\%$ & $\mathbf{n}$ & $\%$ & $\mathbf{n}$ & $\%$ & $\mathbf{n}$ & $\%$ \\
\hline 1 & Paddy - Mono & 35 & 20.00 & 21 & 21.00 & 2 & 2.70 & 58 & 16.60 \\
\hline 2 & Coconut - Mono & 1 & 0.60 & 4 & 4.00 & 19 & 25.30 & 24 & 6.90 \\
\hline 3 & Rubber - Mono & 8 & 4.60 & 3 & 3.00 & 2 & 2.70 & 13 & 3.70 \\
\hline 4 & Coffee \& Pepper & 0 & 0 & 1 & 1.00 & 0 & 0 & 1 & 0.30 \\
\hline 5 & Banana & 1 & 0.60 & 4 & 4.00 & 0 & 0 & 5 & 1.40 \\
\hline 6 & Mixed & 90 & 51.40 & 47 & 47.00 & 38 & 50.70 & 175 & 50.00 \\
\hline 7 & Homestead & 39 & 22.30 & 20 & 20.00 & 13 & 17.30 & 72 & 20.60 \\
\hline 8 & Vegetables & 1 & 0.60 & 0 & 0 & 1 & 1.30 & 2 & 0.60 \\
\hline
\end{tabular}

The distribution of dairy farming systems based on the major crop or cropping pattern of the household observed in the study is presented in Table 2. Mixed farming appeared as the single largest system with 50.0 per cent of the sampled farms being operated on this mode. Farming systems based on mono cultures of paddy, coconut and rubber constituted 27.20 per cent of the farms, while homestead farms accounted to 20.6 per cent of the studied farms. Along with other systems which depended on coffee, pepper, banana and vegetables, monoculture based systems comprised half of all the farms studied. Systems based on crops like maize, onion, cotton, drumstick etc. were reported from Karnataka (Kumar and Desai, 2017), none of which were observed in the present study. In Chitoor district of Andhra Pradesh, dairy farms operated with paddy, groundnut, sugar cane or bajra (Singh and
Pawaria, 2014). Among these, systems other than the one with paddy were not observed in Kerala.

The proportion of specialized farms was comparatively higher among large farms and least in small farms. Distribution of farming systems based on the share of income from different farming activities observed in the study is presented in Table 3. It was also revealed that mixed farming was preferred ( 64.86 per cent) over specialized dairy farming system (34.86 per cent).

The distribution of farms based on dry matter contribution to livestock observed in the present study is given in Table 4. Among all categories of farms, sole livestock production (SLP) group accounted for more than half of the farmers. The overall picture also showed that 57.7 per cent of farms were of SLP type and 42.3 per cent was crop-livestock 
Table 3: Dairy farming systems identified based on major income source

\begin{tabular}{llllll}
\hline \multirow{2}{*}{ Sl. No. } & \multirow{2}{*}{ Basic type of farm } & \multicolumn{3}{c}{ Type of farm based on share of income } \\
\cline { 3 - 5 } & & Srequency & Percentage & Frequency & Mercentage \\
\cline { 3 - 6 } & Small & 55 & 31.40 & 120 & 68.60 \\
2 & Medium & 36 & 36.00 & 64 & 64.00 \\
3 & Large & 31 & 41.30 & 44 & 58.70 \\
4 & Overall & 122 & 34.86 & 227 & 64.86 \\
\hline
\end{tabular}

mixed (C-L) type. About 71 per cent of dairy farmers in Tamil Nadu produced fodder or crop residues to feed livestock (Thirunavukkarasu et al., 2014), which was higher than that observed in the present study. In Gadag district of Karnataka, about $92 \%$ of the farmers adopted mixed farming, which was higher than that in Tamil Nadu and observation from the present study (Radder et al., 2010; Thirunavukkarasu et al., 2014).

The details of productivity of animals under different agroclimatic zones are presented in Fig. 1. The highest wet average was noticed in high ranges $(10.29$ 1/day), with the lowest being in north zone ( $7.48 \mathrm{1} /$ day). The dry average was highest in problem zone and lowest in north zone.

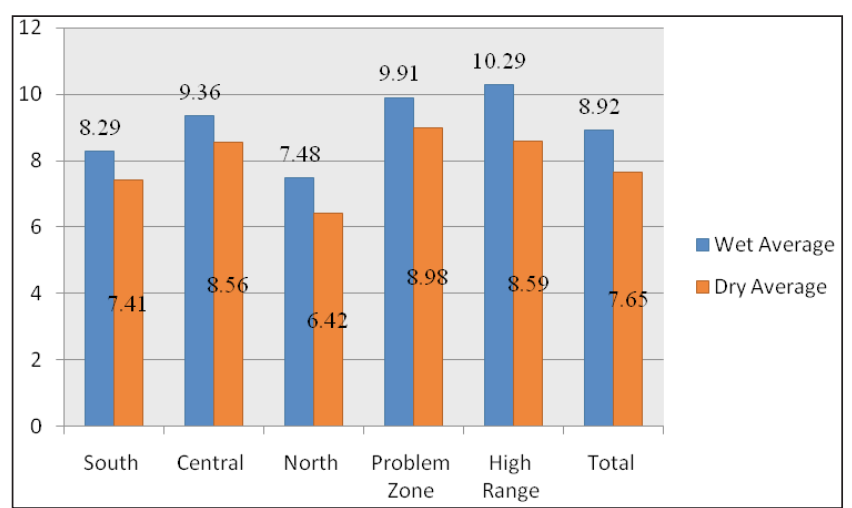

Fig. 1: Average milk production in different agro climatic zones (1/day)

The details of wet and dry average milk production of animals in sampled dairy farms based on cropping system or major crop is presented in Fig. 2. The wet and dry averages were highest in farming system with coffee and pepper as the major crop, while the lowest values for the same were observed in homestead farming system.

The dry and wet averages observed in specialised farms were 8.42 and 7.21 litres per day. The averages were marginally lower than that in mixed farms among which dry and wet averages were 9.17 and 7.88 litres per day. Wet and dry averages were higher in sole livestock production group in which animals did not receive any dry matter of farm origin. The wet and dry averages were 9.09 and 7.71 litres per day respectively as against 8.69 and 7.56 litres per day in farms which provided some quantity of dry matter produced in the farm. The difference could be attributed to deficiencies in the ration of C-L group since SLP group depended more on commercial feeds, with assured quality.

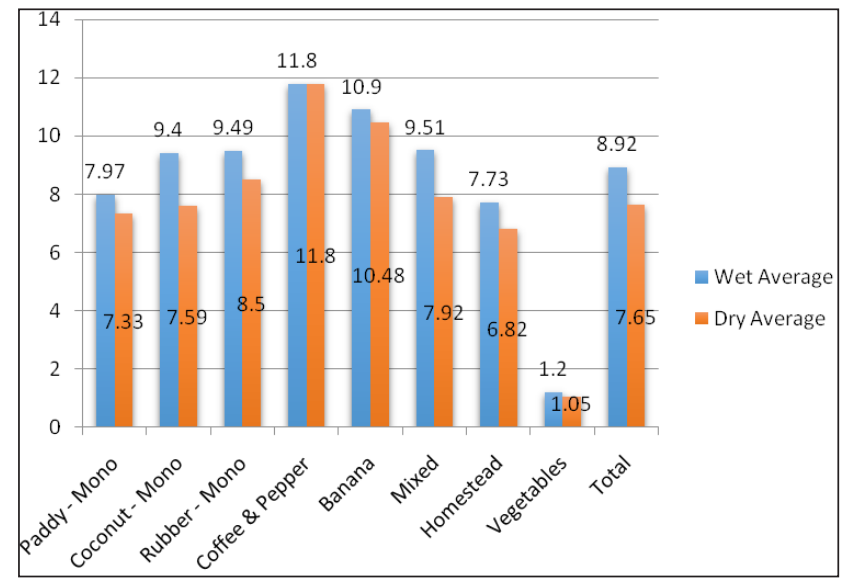

Fig. 2: Average milk production under different cropping systems (1/day)

The fat and SNF content in milk observed after forenoon and after noon milking among different types of farms are presented in Table 5.

Both morning and evening milk had lower SNF than that required by rules (FSSAI, 2011). Fat content of afternoon milk was significantly higher in medium and large farms $(\mathrm{P}<0.01)$. The steep and highly significant variation $(\mathrm{P}<0.01)$ in $\mathrm{SNF}$ among evening samples maybe due to sampling errors but still warrant detailed study. However, 
Table 4: Dairy farming systems identified based on the source of dry matter

\begin{tabular}{llllll}
\hline \multirow{2}{*}{ Sl. No. } & \multirow{2}{*}{ Basic type of farm } & \multicolumn{4}{c}{ Type of farm based on share of income } \\
\cline { 3 - 5 } & & Frequency & Percentage & Frequency & C-L Mixed \\
\cline { 3 - 5 } & Small & 98 & 56.00 & 77 & 44.00 \\
2 & Medium & 51 & 51.00 & 49 & 49.00 \\
3 & Large & 53 & 70.70 & 22 & 29.30 \\
4 & Overall & 202 & 57.70 & 148 & 42.30 \\
\hline
\end{tabular}

Table 5: Fat and SNF content of milk

\begin{tabular}{lllll}
\hline \multirow{2}{*}{ Type of farm } & \multicolumn{2}{c}{ Fat \% (Mean \pm SE) } & \multicolumn{2}{c}{ SNF \% ( Mean \pm SE) } \\
\cline { 2 - 5 } & Forenoon & After noon & Forenoon & After noon \\
\hline Small & $3.89 \pm 0.05$ & $3.7 \pm 0.14^{\mathrm{a}}$ & $8.14 \pm 0.03$ & $6.59 \pm 0.23^{\mathrm{a}}$ \\
Medium & $3.95 \pm 0.71$ & $4.31 \pm 0.11^{\mathrm{b}}$ & $8.2 \pm 0.04$ & $7.62 \pm 0.18^{\mathrm{b}}$ \\
Large & $3.79 \pm 0.65$ & $4.45 \pm 0.10^{\mathrm{b}}$ & $8.13 \pm 0.16$ & $8.04 \pm 0.11^{\mathrm{b}}$ \\
Total & $3.88 \pm 0.70$ & $4.04 \pm 0.08$ & $8.16 \pm 0.71$ & $7.2 \pm 0.13$ \\
\hline
\end{tabular}

Means with different superscripts across a column differ significantly $(\mathrm{P}<0.01)$.

higher values for SNF were also reported from Wayanad and Palakkad districts of Kerala (Thomas and Sasidharan, 2015; Radhika and Ajithkumar, 2018).

Observations with respect to important economic characters like peak yield, lactation yield, service period, number of inseminations per conception, inter calving period, age at first successful service, number of inseminations and age at first calving are presented in Table 6. Test day milk yield was similar in medium and large farms, but was significantly lower $(\mathrm{P}<0.01)$ in small farms. AI per conception, Age at first successful service and age at first calving did not vary significantly across the different types of farms. However service period and inter calving period were lowest in large farms and were significantly different $(\mathrm{P}<0.01)$ from medium and small farms. Peak yield and predicted lactation yields were similar in small and medium farms while it was significantly higher $(\mathrm{P}<0.01)$ in large farms, compared to the other two types.

Results indicated that in general, medium and large farms performed better in several of the traits studied. Large farms had significantly better production with respect to peak yield, test day yield and predicted lactation yields $(\mathrm{P}<0.01)$, besides having lower service period and inter calving period $(\mathrm{P}<0.01)$. However, age at first successful service, number of inseminations per conception and age at first calving remained similar across different types of farms. The probable reasons could be higher revenues in large and medium farms, effective culling and replacement of animals with low productivity. Small holder units are often limited by capital to carry out culling of animals. Another difference could be the availability of labour in large and medium farms and supervision of work by owners or managers.

Age at first calving was similar to that in small scale farms but age at first service and age at first calving were considerably lower in crossbreds of Red Sindhi with Jersey from Tamil Nadu (Vinothraj et al., 2016). Observations with respect to lactation yield, inter calving period and age at first calving were in the range reported by Vijayakumar et al. (2019) from Jersey crossbreds of Tamil Nadu, while service period and the number of inseminations required appeared lower in the present study (Vinothraj et al., 2016; Vijayakumar et al., 2019). The peak yield observed in the study was higher than that reported from Holstein Friesian-Sahiwal crosses of Andhra Pradesh while total lactation yield remained within the range (Lakshmi et al., 2010). The peak yield among small and medium farms in the study were comparable with that in Maharashtra and was marginally lower than that in Haryana, while age at first calving and services per conception remained lower than these states (Kale et al., 2018). Service period and inter calving interval appeared higher than that reported by 
Table 6: Performance of different farm types with respect to economic characters

\begin{tabular}{|c|c|c|c|c|c|c|c|c|c|c|c|c|}
\hline \multirow{3}{*}{ Economic traits } & \multicolumn{12}{|c|}{ Type of farm } \\
\hline & \multicolumn{4}{|c|}{ Small } & \multicolumn{4}{|c|}{ Medium } & \multicolumn{4}{|c|}{ Large } \\
\hline & Min & Max & $\mathbf{n}$ & $\operatorname{Mean} \pm$ SE & Min & Max & n & $\operatorname{Mean} \pm \mathbf{S E}$ & Min & Max & $\mathbf{n}$ & $\operatorname{Mean} \pm \mathrm{SE}$ \\
\hline Peak yield $^{+}$ & 6 & 40 & 176 & $14.63 \pm 0.37^{\mathrm{a}}$ & 5 & 35 & 173 & $14.80 \pm 0.42^{\mathrm{a}}$ & 6 & 40 & 115 & $18.64 \pm 0.54^{b}$ \\
\hline Test day yield ${ }^{+}$ & 3 & 22 & 176 & $9.61 \pm 0.30^{\mathrm{a}}$ & 2 & 26 & 105 & $11.26 \pm 0.48^{b}$ & 5 & 24 & 37 & $12.58 \pm 0.68^{b}$ \\
\hline Lactation yield $1^{+}$ & 1293 & 8620 & 176 & $3152.14 \pm 80.16^{\mathrm{a}}$ & 1078 & 7543 & 173 & $3189.15 \pm 90.19^{\mathrm{a}}$ & 1293 & 8620 & 115 & $4016.47 \pm 116.11^{b}$ \\
\hline Lactation yield $2^{+}$ & 1186 & 6012 & 175 & $2608.63 \pm 80.16^{\mathrm{a}}$ & 1270 & 6178 & 104 & $2901.37 \pm 100.78^{a}$ & 1649 & 5723 & 36 & $3219.5 \pm 163.70^{\mathrm{b}}$ \\
\hline Service period $\S$ & 88 & 1050 & 130 & $190.95 \pm 11.11^{\mathrm{a}}$ & 70 & 446 & 74 & $170.64 \pm 8.53^{\mathrm{a}}$ & 60 & 303 & 33 & $128.53 \pm 7.96^{\mathrm{b}}$ \\
\hline Inter calving period ${ }^{\S}$ & 340 & 1330 & 130 & $470.95 \pm 11.11^{\mathrm{a}}$ & 366 & 726 & 74 & $455.32 \pm 7.98^{\mathrm{a}}$ & 340 & 583 & 33 & $408.53 \pm 7.96^{\mathrm{b}}$ \\
\hline AI per conception & 1 & 10 & 130 & $2.29 \pm 0.15^{\mathrm{a}}$ & 1 & 5 & 74 & $1.96 \pm 0.12^{\mathrm{a}}$ & 1 & 3 & 33 & $1.8 \pm 0.13^{\mathrm{a}}$ \\
\hline First successful service ${ }^{\#}$ & 12 & 39 & 44 & $21.71 \pm 0.8^{\mathrm{a}}$ & 15 & 46 & 36 & $23.87 \pm 1.14^{\mathrm{a}}$ & 12 & 42 & 12 & $19.23 \pm 2.37^{\mathrm{a}}$ \\
\hline First calving \# & 21 & 48 & 44 & $30.71 \pm 0.8^{\mathrm{a}}$ & 24 & 55 & 36 & $32.87 \pm 1.14^{\mathrm{a}}$ & 21 & 51 & 12 & $28.23 \pm 2.37^{\mathrm{a}}$ \\
\hline
\end{tabular}

Lactation yield 1- Predicted from peak yield; Lactation yield 2 - Predicted from test day yield; Means bearing different superscripts in a row are significantly different $(\mathrm{P}<0.01) ;{ }^{+}$Yield in litres; \$Period in days; ${ }^{*}$ Age in months.

Kale et al. (2018) from states like Haryana, Maharashtra and Odissa. Though Deoni-Holstein Friesian crossbreds (Bhutkar et al., 2014) had higher age at first calving, service and inter calving periods were lower than that in small and medium farms in the present study. Possible reasons included failure of farmers to notice heat or actual delay in initiation of post partum ovarian activity among animals sampled for the study. The interval between two successive calvings should be 12 to 15 months, with service period of 90 to 180 days for profitable dairy farming (KAU, 2010). Results of the study clearly indicated that service period and inter calving interval exceeded theoretical limits for profitability in small farms suggesting that many of them incurred net loss.

The presence of large farms with more than 10 milch cattle was less than one per cent in the present study. This may be due to large initial capital requirement, besides difficulties in arranging labour beyond family work and limitations in availability and procurement of fodder. The predominance of mixed farmers and homestead farmers are typical features of agriculture and dairying in Kerala and were confirmed again in the present study. The observation that SLP farmers were slightly more than CL group indicated that dairy farming was evolving into an enterprise on its own, rather than relying on more traditional crop based systems. In Kerala scenario, reduction in availability of straw without any other significant source of dry matter to livestock from agriculture crops, farmers have to depend more on purchased feeds and fodder. One of the limitations of present study was that all the farmers sampled were members of dairy co-operatives. Many farmers might not be members of co-operatives, since they prefer to sell milk directly to market, rather than to the society. The results of the study also exposed several areas which are amenable to intervention like reduction of inter calving interval and service period to improve profitability of dairy farming in Kerala.

\section{CONCLUSION}

The study identified eight different dairy farming systems based on major crop or cropping pattern. Vast majority of dairy farmers in Kerala were small holders and large dairy units accounted to less than one per cent of the total units. Examination of key economic traits indicated that age at first calving and inter calving period were much higher than theoretical optima, which eroded profitability. The average SNF content in milk observed in the study is lower than legal requirement of 8.3 per cent.

\section{ACKNOWLEDGEMENTS}

The support from Animal Husbandry and Dairy Development Department, Government of Kerala towards data collection is gratefully acknowledged.

\section{REFERENCES}

Bhutkar, S.S., Thombre, B.M. and Bainwad, D.V. 2014. Studies on effect of non - genetic factors on reproduction traits in Holstein Friesian $\times$ Deoni cows. J. Agric. Vet. Sci., 7(12): 1519. 
FSSAI, 2011. Food safety and standards (food products standards and food additives) regulations, Ministry of health and family welfare, Government of India.

Kale, R.B., Ponnusamy, K., Chakravarty, A.K., Mohammad A. and Sendhil R. 2018. Productive and reproductive performance of cattle and buffaloes reared under farmers' management in differential dairy progressive states in India. Indian J. Anim. Res., 52(10): 1513-1517.

KAU, 2010. Package of practices and recommendations: Veterinary and Animal husbandry. ( $6^{\text {th }}$ Ed.). Kerala Agricultural University Press, Mannuthy, Thrissur, pp. 266.

Kumar, V.S.N. and Desai, B.K. 2017. Dairy based farming system models for livelihood security of small and marginal farmers of N-E Karnataka. Int. J. Chem. Stud., 5(3): 805-808.

Lakshmi, B.S., Gupta, B.R., Prakash, M.G., Sudhakar, K. and Sharma, S. 2010. Genetic analysis of the production performance of Frieswal cattle. Tamil Nadu J. Vet. Anim. Sci., 6(5): 215-222.

NARP, 1989. National agricultural research project (ICAR) status report. Kerala Agricultural University Press, Mannuthy, Thrissur, pp. 125.

Radder, S.K, Bhanj, S.K. and Kaul, P.N. 2010. Cattle rearing patterns of farmers in northern Karnataka. IJRS., 17(1): 1-5.

Radhika, G. and Ajithkumar, S. 2018. Low solids not fat percentage in milk of crossbred cows in Wayanad district of Kerala, India-a retrospective study. Int. J. Sci. Environ. Technol., 7(6): 1962-1969.

Rejula, K. and Singh, R. 2015. An analysis of changing land use pattern and cropping pattern in a scenario of increasing food insecurity in Kerala state. Economic Affairs., 60(1): 123-129.
Sastry, N.S.R. and Thomas, C.K. 2015. Livestock Production Management (15 ${ }^{\text {th }}$ Ed.). Kalyani publishers, New, Delhi, pp. 912.

Singh, A. and Pawariya, V. 2014. Dairy based farming system in Chittoor district of Andhra Pradesh. In: Agriculture: towards a new paradigm of sustainability. Mishra, G.C. Excellent publishing house, Vasant Kunj, New Delhi, pp. 1-4.

Thirunavukkarasu, D., Jothilakshmi, M., Murugesan, S. and Doraisamy, K.A. 2014. Transition of smallholder dairy farming system - a micro study in Tamil Nadu, India. Livest. Res. Rural, 26(5): 2014.

Thomas, J.J. 2011. Paddy cultivation in Kerala. RAS., 1(2): 215226.

Thomas, M. and Sasidharan, M. 2015. Factors affecting milk fat percentage and solids-not-fat percentage and milk price of dairy cattle in humid tropics. $A A A S ., \mathbf{0 3}(1)$ : 11-17.

Vijayakumar, P., Singaravadivelan, A., Silambarasan, P., Ramachandran, M. and Churchil, R. 2019. Production and reproduction performances of crossbred jersey cows. Vet. Res. Int., 7(2): 56-59.

Vinothraj, S., Subramaniyan, A.,Venkataramanan, R., Joseph, C. and Sivaselvam, S.N. 2016. Genetic evaluation of reproduction performance of Jersey $\times$ Red Sindhicrossbred cows. Vet. World, 9(9): 1012-1017.

Viswanathan, P.K. 2014. The rationalization of agriculture in Kerala: implications for the natural environment, agroecosystems and livelihoods. Agrarian South: J. Polit. Econ., 3(1): 63-107. 
